\title{
Is lactate clearance impaired in septic shock?
}

\author{
Thiago Domingos Corrêa ${ }^{1,2}$, Jukka Takala ${ }^{2}$ and Stephan Matthias Jakob²* \\ See related research by Tapia et al., http://www.ccforum.com/content/19/1/188
}

In a recent article in Critical Care, Tapia and colleagues evaluated the relationship between exogenous lactate clearance and liver perfusion in a short-term model of endotoxemic shock [1]. The authors concluded that the very low portal-hepatic vein lactate gradient was indicative of the inability of the liver to metabolize the increased lactate load. Although we believe that the authors addressed an important issue, we have some concerns regarding their methodology.

The portal-hepatic vein lactate gradient as a surrogate of liver lactate metabolism may be misleading, since systemic hyperlactatemia increases hepatic arterial lactate delivery and may result in net mesenteric lactate uptake [2]. Given a contribution of $15 \%$ of the hepatic artery to total hepatic blood flow [3], hepatic lactate uptake in endotoxemic animals in the study by Tapia and colleagues (portal vein plus hepatic artery lactate delivery minus hepatic vein lactate efflux) would have roughly doubled during their experiment. At the same time, the net mesenteric lactate uptake (estimated from the product of portal vein flow and portal vein-arterial lactate gradient) increased more than sevenfold. Given the increased mesenteric and hepatic lactate uptake in the study by Tapia and colleagues, we wonder how it is possible that exogenous lactate clearance decreased by a factor of more than 20 during their experiment [1]. Finally, the authors took only six arterial lactate samples until 20 min after completion of L-lactate infusion as opposed to 20 samples with an extension up to $60 \mathrm{~min}$ after completion of L-lactate infusion in the original literature $[4,5]$ and did not present the results, although this was their main finding.

\section{Competing interests}

The authors declare that they have no competing interests.

\section{Author details}

${ }^{1}$ Intensive Care Unit, Hospital Israelita Albert Einstein, Av. Albert Einstein, 627/701, São Paulo 05652-000, Brazil. ²Department of Intensive Care Medicine, Inselspital, Bern University Hospital and University of Bern, Freiburgstrasse 10, Bern 3010, Switzerland.

Published online: 10 September 2015

\section{References}

1. Tapia P, Soto D, Bruhn A, Alegria L, Jarufe N, Luengo C, et al. Impairment of exogenous lactate clearance in experimental hyperdynamic septic shock is not related to total liver hypoperfusion. Crit Care. 2015;19:188.

2. Barthelmes D, Jakob SM, Laitinen S, Rahikainen S, Ahonen H, Takala J. Effect of site of lactate infusion on regional lactate exchange in pigs. $\mathrm{Br} J$ Anaesth. 2010;105:627-34.

3. Gorrasi J, Eleftheriadis A, Takala J, Brandt S, Djafarzadeh S, Bruegger LE, et al. Different contribution of splanchnic organs to hyperlactatemia in fecal peritonitis and cardiac tamponade. Biomed Res Int. 2013;2013:251084.

4. Connor H, Woods HF, Ledingham JG, Murray JD. A model of L(+)-lactate metabolism in normal man. Ann Nutr Metab. 1982;26:254-63.

5. Levraut J, Ciebiera JP, Chave S, Rabary O, Jambou P, Carles M, et al. Mild hyperlactatemia in stable septic patients is due to impaired lactate clearance rather than overproduction. Am J Respir Crit Care Med. 1998;157:1021-6.

\footnotetext{
* Correspondence: stephan.jakob@insel.ch

${ }^{2}$ Department of Intensive Care Medicine, Inselspital, Bern University Hospital and University of Bern, Freiburgstrasse 10, Bern 3010, Switzerland

Full list of author information is available at the end of the article
}

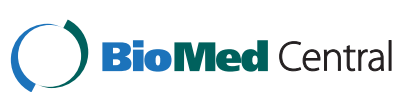

(C) 2015 Corrêa et al. Open Access This article is distributed under the terms of the Creative Commons Attribution 4.0 International License (http://creativecommons.org/licenses/by/4.0/), which permits unrestricted use, distribution, and reproduction in any medium, provided you give appropriate credit to the original author(s) and the source, provide a link to the Creative Commons license, and indicate if changes were made. The Creative Commons Public Domain Dedication waiver (http://creativecommons.org/publicdomain/zero/1.0/) applies to the data made available in this article, unless otherwise stated. 